\begin{tabular}{|c|c|}
\hline & $\begin{array}{l}\text { International Journal of Trend in Scientific } \\
\text { Research and Development (IJTSRD) }\end{array}$ \\
\hline 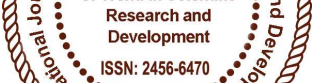 & International Open Access Journal \\
\hline 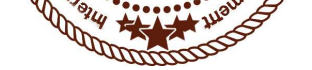 & ISSN No: 2456 - 6470 | www.ijtsrd.com | Volume - 2 | Issue - 2 \\
\hline
\end{tabular}

\title{
Application of immobilized banana peels (Musa paradisiaca L.) into calcium alginate beads for removal of chromium (VI) from aqueous solution
}

\section{ABSTRACT}

The capacity of banana peels (Musa paradisiaca L.) immobilized into calcium alginate beads to remove chromium (VI) ions from aqueous solution was studied. Immobilization enhances sorption of chromium (VI) and repetitive use of sorbent could be achieved. The immobilized banana peels in to calcium alginate beads was characterized by FTIR, SEM and XRD. The influence of several operating experimental parameters such as solution $\mathrm{pH}$, biosorbent dose concentration, initial chromium (VI) ions concentration, contact time, temperature and agitation rate determine the efficiency of metal uptake by biosorbent. Desorption efficiency of banana peels immobilized in to calcium alginate beads was highest for sulphuric acid followed by hydrochloric acid and nitric acid. The equilibrium isotherm data were comparing by using the Langmuir, Freundlich, DKR and Temkin adsorption isotherm models in which Langmuir isotherm was found to be fitted best. The Kinetics of sorption of chromium (VI) were described by a pseudo-First-order kinetic, pseudo-second-order kinetic, Elovich and Weber and Morris intra-particle diffusion model in which pseudo second order model was found to be fitted best. Thermodynamic studies were also carried out. The results showed that immobilized banana peels (Musa paradisiaca L.) in to calcium alginate beads was a low-cost promising sorbent for sequester of chromium (VI) from wastewater.
Keywords: biosorption, desorption, chromium (VI), banana peels (Musa paradisiaca L.), Immobilization, calcium alginate beads, adsorption isotherm, adsorption kinetics, thermodynamic study.

\section{INTRODUCTION:}

The increase of industrial activities has intensified environmental pollution problems and the deterioration of several ecosystems with the accumulation of many pollutants, especially heavy metals. Effluents containing heavy metals are discharged from various industrial processes. These pollutants concentration must be reduced to meet ever increasing legislative standards, and recovered where feasible. Chromium has long been used in electroplating, leather tanning, metal finishing and chromate manufacturing industries (Prakasham et al., 1999). Normally, in contaminated water is primarily present in the form of chromium (VI) as chromate $\left(\mathrm{CrO}_{4}{ }^{2-}\right)$ and dichromate $\left(\mathrm{Cr}_{2} \mathrm{O}_{7}{ }^{2-}\right)$. When chromium enters the gastric system, epigastric pain, nausea, vomiting, severe diarrhoea, corrosion of skin, respiratory tract and lung carcinoma are noticed. The discharge limit from industry is less than $1 \mathrm{mg} / \mathrm{L}$. Chromium is hazardous to health when its limit in potable water exceeds $0.5 \mathrm{mg} / \mathrm{L}$ (Sharma et al., 2015). 
Traditional / conventional treatment techniques for water purification need very expansive and continuous input of chemicals becomes impracticable and uneconomical which causes further damage to the environment. Therefore, it is required to produce an easy, effective, economic and eco-friendly technique for wastewater treatment (Veglio and Beolchini, 1997; Volesky, 2001). Biosorption is a cost- effective and eco-friendly technique for removal of heavy metals. Biosorption may be defined as removal of substances from solution by biological material (Gadd, 1992; Bhalerao, 2011).

The Powdered form provides some difficulties associated with separation of biomass after adsorption, mass loss after regeneration and small particle size which make it difficult to use in column applications. Therefore, modification of raw biomass can improve the sorption capacity. The modification can be achieved by physical processes, chemical processes, and chemical entrapment of the biomass to form membranes, beads, pellets or granular biosorbents (Bhatti et al., 2010). Alginate has been applied in preparation of beads for biosorption. The idea is entrap the biomass and prevent its loss while substrates and products are allowed to pass through the support material (Sharmila et al., 2012). Alginate is a polyelectrolyte material commonly present in gel form. It possesses properties such as a relatively inert aqueous environment, encapsulation process free of solvents, ability to control the porosity with single coating, procedures to make a favorable matrix for entrapment of organic and inorganic compounds.

In the present research work, banana peels (Musa paradisiaca L.) is an agro-industrial based waste material belongs to the family Scitaminaceae and subfamily Musaceae and these materials have the potential to sequester heavy metals from aqueous solutions. The present research describes the increased utilization and efficiency of banana peels (Musa paradisiaca L.) biomass when immobilized into calcium alginate beads for the biosorption of chromium (VI) from wastewater. The study was extended with the objective for estimation and calculation of various parameters affecting the biosorption such as solution $\mathrm{pH}$, biosorbent dose concentration, initial chromium (VI) ions concentration, contact time, temperature and agitation rate. Adsorption isotherms models and kinetics models were employed to understand the probable biosorption mechanism. Thermodynamic study was also carrying out to estimate the standard free change $\left(\Delta G^{0}\right)$, standard enthalpy change $\left(\Delta H^{0}\right)$ and standard entropy change $\left(\Delta S^{0}\right)$.

\section{MATERIALS AND METHODS}

\section{Chemical and reagent:}

All the chemicals and reagents used were of analytical reagent (AR) grade. Double distilled water was used for all experimental work including the preparation of metal solutions. The desired $\mathrm{pH}$ of the metal ion solution was adjusted with the help of dilute hydrochloric acid and sodium hydroxide.

\section{Preparation of chromium (VI) standard solution:}

The stock solution of 1000 ppm of chromium (VI) was prepared by dissolving $0.7072 \mathrm{~g}$ of potassium dichromate $\left(\mathrm{K}_{2} \mathrm{Cr}_{2} \mathrm{O}_{7}\right)$ (AR grade) (previously dried at $50^{\circ} \mathrm{C}$ for one hour) in $250 \mathrm{ml}$ of double distilled water and further desired test solutions of chromium (VI) were prepared using appropriate subsequent dilutions of the stock solution.

\section{Preparation of biosorbent:}

Fresh banana peels (Musa paradisiaca L.) were collected from domestic wastes, as its availability and transportation was easy. The peels were washed several times with tap water and followed by distilled water. The washed material then cut in to small pieces and banana peels was first dried, in sun light for 10 days and then in an oven at $50^{\circ} \mathrm{C}$. The moisture content was lost from it and the color change was observed from yellow to brownish black. The dried material was finely ground and screened through the sieves of cut size of $100-200 \mu \mathrm{m}$. The dried biosorbent powder was stored in air tight glass bottles to protect it from moisture.

\section{Immobilization of biosorbent:}

$2 \%$ solution of calcium chloride was prepared by dissolving $2.0 \mathrm{~g}$ anhydrous calcium chloride in $100 \mathrm{ml}$ distilled water. $0.5 \mathrm{~g}$ banana peels powder was mixed with $0.5 \mathrm{~g}$ sodium alginate powder and slurry was prepared by adding appropriate amount of distilled water with constant stirring to avoid the formation of lumps. This mixture was extruded as droplet in $2 \%$ solution of calcium chloride through a glass nozzle (1.0 cm length and $2.5-3 \mathrm{~mm}$ internal diameter) and the solution was stirred to avoid clumping of immobilized beads. Beads were formed of 
approximately $3-3.5 \mathrm{~mm}$ diameter. The beads were allow curing for 1 hour at $4^{\circ} \mathrm{C}$ in the same solution and then washed thoroughly with distilled water. After that it was stored in refrigerator for further use as biosorbent.

\section{Instrumentation:}

The $\mathrm{pH}$ of the solution was measured by digital $\mathrm{pH}$ meter (EQUIP-TRONICS, model no. Eq-610) using a combined glass electrode. The concentration of chromium (VI) in the solutions before and after equilibrium was determined by using Inductively Coupled Plasma-Atomic Emission Spectroscopy (ICP-AES) technique. Biosorbent was characterized by Fourier Transform Infrared (FTIR), Scanning Electron Microscope (SEM) and X-ray diffraction (XRD).

Characterization of biosorbent by Fourier Transform Infrared (FTIR) analysis: The Fourier Transform Infrared (FTIR) spectroscopy was used to identify the functional groups present in the biosorbent. The biomass samples were examined using FTIR spectrometer (model:FT/IR-4100typeA) within range of $400-4000 \mathrm{~cm}^{-1}$. All analysis was performed using $\mathrm{KBr}$ as back ground material. In order to form pellets, $0.02 \mathrm{~g}$ of biomass was mixed with $0.3 \mathrm{~g} \mathrm{KBr}$ and pressed by applying pressure.

Characterization of biosorbent by Scanning Electron Microscope (SEM) analysis: The Scanning Electron Microscope (SEM) was used to see the porosity of the biosorbent. The samples were covered with a thin layer of gold and an electron acceleration voltage of $10 \mathrm{KV}$ was applied and then Scanning Electron Micrograph was recorded.

\section{Characterization of biosorbent by X-ray diffraction (XRD) analysis:}

X-ray diffraction (XRD) was used for the qualitative and quantitative determination of solid samples of biosorbent. It works on the principle that X-ray diffraction pattern is unique for each sample. This pattern from XRD was compared with a known compound and the chemical compound was identified.

\section{Experimental procedure:}

The static (batch) method was employed at temperature $\left(30^{\circ} \mathrm{C}\right)$ to examine the biosorption of chromium (VI) by biosorbent. The method was used to determine the adsorption capacity, stability of biosorbent and optimum biosorption conditions. The parameters were studied by combining biosorbent with chromium (VI) solution in $250 \mathrm{ml}$ separate reagent bottles. The reagent bottles were placed on a shaker with a constant speed and left to equilibrate. The samples were collected at predefined time intervals, centrifuged, the content was separated from the adsorbent by filtration, using Whatmann filter paper and amount of chromium (VI) in the supernatant/filtrate solutions was determined by ICPAES. The following equation was used to compute the percent removal ( $\%$ Adsorption) of chromium (VI) by the adsorbent,

\section{$\%$ Adsorption $=\frac{\left(C_{i}-C_{e}\right)}{C_{i}} \times 100$}

where $C_{i}$ and $C_{e}$ are the initial concentrations and equilibrium concentrations of the chromium (VI) in $\mathrm{mg} / \mathrm{L}$.

The equilibrium adsorptive quantity $\left(q_{e}\right)$ was determined by the following equation,

$q_{e}=\frac{\left(C_{i}-C_{e}\right)}{w} \times V$

where $q_{e}$ (mg metal per $\mathrm{g}$ dry biosorbent) is the amount of chromium (VI) biosorbed, $V$ (in liter) is the solution volume and $w$ (in gram) is the amount of dry biosorbent used.

\section{Desorption Study:}

To evaluate desorption efficiency, chromium (VI) loaded biosorbent was dried after equilibrium sorption experiments. The dried biosorbent was contacted with $0.1 \mathrm{M}$ nitric acid $\left(\mathrm{HNO}_{3}\right), 0.1 \mathrm{M}$ hydrochloric acid $(\mathrm{HCl})$ and $0.1 \mathrm{M}$ sulphuric acid $\left(\mathrm{H}_{2} \mathrm{SO}_{4}\right)$ separately for 3 hours to allow chromium (VI) to be release from biosorbent. The samples were separated from the biosorbents by filtration, using Whitman filter paper and amount of chromium (VI) in the supernatant/filtrate solutions was determined by ICPAES to find out desorption efficiency. Desorption efficiency was calculated from the amount of metal adsorbed on the biosorbent and the final metal concentration in the biosorption medium. 
Desorption efficiency $(\%)=\frac{\text { released metal ions in } \mathrm{mg} / \mathrm{L}}{\text { initially adsorbed metal ions } \mathrm{in} \mathrm{mg} / \mathrm{L}} \times 100$

\section{Results and discussion}

\section{Characterization of biosorbent by Fourier Transform Infrared (FTIR) analysis:}

The Fourier Transform Infrared (FTIR) spectroscopy was used to identify the functional groups present in the biosorbent. The biosorbent samples were examined using FTIR spectrometer (Model: FT/IR4100typeA) within range of $400-4000 \mathrm{~cm}^{-1}$. All analysis was performed using $\mathrm{KBr}$ as back ground material. In order to form pellets, $0.02 \mathrm{~g}$ of biomass was mixed with $0.3 \mathrm{~g} \mathrm{KBr}$ and pressed by applying pressure. To investigate the functional groups of biosorbent and metal loaded with biosorbent, a FTIR analysis was carried out and the spectra are shown in Fig.1. ( $a$ and b). As seen in the figure unloaded biosorbent displays a number of absorption peaks, reflecting the complex nature of biosorbent. The broad peak at $3440 \mathrm{~cm}^{-1}$ is the indicator of $-\mathrm{OH}$ and $\mathrm{NH}$ groups. The peaks located at $1628 \mathrm{~cm}^{-1}$ are characteristics of carbonyl group. The presence of $\mathrm{OH}$ group along with carbonyl group confirms the presence of carboxyl acid groups in the biosorbent. The peaks observed at $1076 \mathrm{~cm}^{-1}$ are due to $\mathrm{C}-\mathrm{H}$ and $\mathrm{C}-\mathrm{O}$ bonds. The $-\mathrm{OH}, \mathrm{NH}$, carbonyl and carboxyl groups are important sorption sites. As compared to simple biosorbent, biosorbent loaded with chromium (VI) the broadening of $-\mathrm{OH}$ peak at $3440 \mathrm{~cm}^{-1}$ and carbonyl group peak at $1628 \mathrm{~cm}^{-1}$ was observed. This indicates the involvement of hydroxyl and carbonyl groups in the biosorption of chromium (VI) ions.

\section{Characterization of biosorbent by Scanning Electron Microscope (SEM) analysis:}

SEM analysis was carried out for the biosorption of chromium (VI) on the surfaces of the calcium alginate immobilized banana peels (Musa paradisiaca L.). The SEM images of calcium alginate immobilized banana peels (Musa paradisiaca L.) before and after biosorption of chromium (VI) are shown in Figure 2 (a) and 2 (b) respectively.

These micrographs represent a porous structure with large surface area. The SEM clearly demonstrated that there is more uniformity after biosorption of chromium (VI) onto biosorbent in comparison to before biosorption. It was evident from the micrographs that the biosorbents presents an unequal structure before chromium (VI) biosorbed. The number of canals in the biosorbents was higher in the initial case. The chromium (VI) biosorbed on the cell wall matrix and created stronger cross linking and uniformity on the surface of biosorbent.

\section{X-ray diffraction analysis (XR-D) analysis:}

XRD pattern of the unloaded and loaded biosorbent with the chromium (VI) solution is shown in Figure 3(a) and 3(b). The XRD spectra of unloaded chromium (VI) which shows broad peaks were obtained instead of sharp peaks indicating the sample was poorly crystalline. The XRD spectra of loaded chromium (VI) exhibit strong peaks at $2 \theta$ value $20.36^{\circ}, 31.60^{\circ}$ and $45.40^{\circ}$ corresponding to 277.567 , 389.259 and 189.6950 planes, respectively. Also, XRD pattern of chromium (VI) loaded biosorbent shows the presence of phases of $\mathrm{Cr}_{2} \mathrm{O}_{7}{ }^{2-}$ and $\mathrm{HCrO}_{4}{ }^{-}$ which indicates that some of the chromium (VI) is converted into $\mathrm{Cr}_{2} \mathrm{O}_{7}{ }^{2-}$ and $\mathrm{HCrO}_{4}^{-}$at $\mathrm{pH}$ 4. So it was concluded that, chromium (VI) finally get adsorbed over the surface of biosorbent.

\section{Effect of pH:}

For chromium (VI) stability $\mathrm{pH}$ is one of the most important parameter which controls the surface properties of biosorbents, functional groups and ionic state of metal's species. The optimization of $\mathrm{pH}$ was done by varying the $\mathrm{pH}$ in the range of $1-8$ for bisorption of chromium (VI) and $\mathrm{pH}$ trend observed in this case is shown in Figure 4. It was found that at $\mathrm{pH}$ 4 the biosorption process was maximum with $88.08 \%$ and after increasing $\mathrm{pH}$, biosorption was decreases. According to the solubility equilibrium of chromium, $\mathrm{HCrO}_{4}^{-}$is the dominant species of chromium (VI) at a $\mathrm{pH}$ 4. As the $\mathrm{pH}$ increases, the dominant form of chromium becomes $\mathrm{CrO}_{4}{ }^{2-}$ and $\mathrm{Cr}_{2} \mathrm{O}_{7}{ }^{2-}$. Furthermore, the surface of biosorbent may be positively charged at $\mathrm{pH}$ 4. Therefore, at this $\mathrm{pH}$ it is likely to be adsorbed chromium (VI) onto biosorbent through electrostatic attraction and /or by the binding of $\mathrm{HCrO}_{4}{ }^{-}$to acidic functional groups on the surface of biosorbent. Also at $\mathrm{pH} 4$, the number of protons available on the surface of biosorbent increases, which increases the attraction between $\mathrm{HCrO}_{4}^{-}$\& biosorbent and increases the sorption capacity (Rao et al., 1992). As the $\mathrm{pH}$ of the solution increases, charges on the surface of biosorbent becomes negative, this leads to generation of repulsive forces between chromium (VI) \& 
biosorbent and inhibits adsorption and resultantly percent chromium (VI) uptake may slightly decrease.

\section{Effect of biosorbent dose concentration:}

Biosorbent dosage is an important parameter studied while conducting batch mode studies. The sorption capacity of banana peels (Musa paradisiaca L.) onto chromium (VI) by varying its dosage from $1 \mathrm{~g} / \mathrm{L}$ to 15 $\mathrm{g} / \mathrm{L}$ is shown in Figure 5. From the results it was found that biosorption of chromium (VI) increases with increase in biosorbent dosage and is highly dependent on biosorbent concentration. Increase in biosorption by increase in biosorbent dose is because of increase of ion exchange site ability, surface areas and the number of available biosorption sites (Naiya et al., 2009). The point of saturation for banana peels (Musa paradisiaca L.) was found at $5 \mathrm{~g} / \mathrm{L}$ of biosorbent dose with $88.13 \%$ of removal efficiency. The decrease in efficiency at higher biosorbent concentration could be explained as a consequence of partial aggregation of adsorbent which results in a decrease in effective surface area for metal uptake (Karthikeyan et. al. 2007). Hence, biosorbent dose 5 $\mathrm{g} / \mathrm{L}$ was chosen for all further studies.

\section{Effect of initial chromium (VI) concentration:}

The effect of initial Chromium (VI) concentration from $5 \mathrm{mg} / \mathrm{L}-250 \mathrm{mg} / \mathrm{L}$ on the removal of Chromium (VI) from aqueous solutions at biosorbent dose concentration $5 \mathrm{~g} / \mathrm{L}$ and at optimum $\mathrm{pH} 4$ at $30^{\circ} \mathrm{C}$ was studied. On increasing the initial chromium (VI) concentration, the total chromium (VI) ions uptake decreased slightly when chromium (VI) concentration increases from $5 \mathrm{mg} / \mathrm{L}-250 \mathrm{mg} / \mathrm{L}$.

\section{Effect of contact time:}

In order to optimize the contact time for the maximum uptake of chromium (VI) onto biosorbent, contact time was varied between 10 minutes- 240 minutes on the removal of chromium (VI) from aqueous solutions in the concentration of chromium (VI) $10 \mathrm{mg} / \mathrm{L}$ and biosorbent dose $5 \mathrm{~g} / \mathrm{L}$ at optimum $\mathrm{pH} 4.0$ at $30^{\circ} \mathrm{C}$. The results obtained from the biosorption capacity of chromium (VI) onto banana peels (Musa paradisiaca L.) showed that the biosorption increases with increase in contact time until it reached equilibrium. The optimum contact time for biosorption of chromium (VI) ions onto banana peels (Musa paradisiaca L.) was 180 minutes with $89.06 \%$ removal. The rapid uptake of chromium (VI) is due to the availability of ample active sites for sorption. A further increase in the contact time has a negligible effect on the biosorption capacity of chromium (VI) biosorption. So a contact time of 180 minute was fixed for further experiments.

\section{Effect of temperature:}

The effect of temperature on removal of chromium (VI) from aqueous solutions using calcium alginate immobilized banana peels (Musa paradisiaca L.) was studied at different temperatures from $20^{\circ} \mathrm{C}-40^{\circ} \mathrm{C}$. The influence of temperature is depicted in Figure 8. The percentage removal of chromium (VI) increased from $78.03 \%$ to $87.60 \%$ in the range of temperature 20 $40^{\circ} \mathrm{C}$ respectively. It can be clearly seen from the figure that, increase in temperature the percentage removal increased slowly. The increase in biosorption capacity with the increase in temperature indicates that the biosorption process is endothermic in nature.

\section{Effect of agitation rate:}

The effect of agitation rate on removal of chromium (VI) from aqueous solutions at biosorbent dose 10 $\mathrm{mg} / \mathrm{ml}$ and at optimum $\mathrm{pH} 4$ at $30^{\circ} \mathrm{C}$ was studied at different agitation rate such as $40 \mathrm{rpm}, 80 \mathrm{rpm}, 120$ $\mathrm{rpm}, 160 \mathrm{rpm}$ and 200rpm. The efficiency was highest at $120 \mathrm{rpm}$ with percentage removal $87.67 \%$. So, 120 rpm was chosen for all further biosorption studies.

\section{Desorption study:}

In application of real wastewater, desorption of heavy metal ions in the biosorbent is important process. calcium alginate immobilized banana peels ( Musa paradisiaca L.) was the most effective waste biosorbent with desorption efficiency $67.15 \%(0.1 \mathrm{M}$ hydrochloric acid), 82.99\% (0.1 M nitric acid) and $85.80 \%$ (0.1 M sulphuric acid).

Sulphuric acid has shown highest desorbed capacity of chromium (VI) followed by hydrochloric acid and nitric acid from calcium alginate immobilized banana peels (Musa paradisiaca L.).

\section{Adsorption isotherm models}

The analysis of the adsorption isotherms data by fitting them into different adsorption isotherm models is an important step to find the suitable model that can be used for design process. The experimental data were applied to the two-parameter adsorption isotherm models: Langmuir, Freundlich, DubininKaganer-Redushkevich (DKR) and Temkin. 
Adsorption isotherms results for biosorption of Chromium (VI) by banana peels (Musa paradisiaca L.) is shown below;

Langmuir adsorption isotherm (Langmuir, 1918): The Langmuir equation, which is valid for monolayer sorption onto a surface of finite number of identical sites, is given by;

$$
q=\frac{q_{m} b C_{e}}{1+b C_{e}}
$$

where $q_{m}$ is the maximum biosorption capacity of adsorbent $\left(\mathrm{mg} \mathrm{g}^{-1}\right) . b$ is the Langmuir biosorption constant $\left(\mathrm{L} \mathrm{mg}^{-1}\right)$ related to the affinity between the biosorbent and biosorbate.

Linearized Langmuir isotherm allows the calculation of adsorprtion capacities and Langmuir constants and is represented as:

$$
\frac{1}{q}=\frac{1}{q_{m} b C_{e}}+\frac{1}{q_{m}}
$$

The linear plots of $1 / q$ vs $1 / c_{e}$ is shown in Figure 10 (a). The two constants $b$ and $q_{m}$ are calculated from the slope $\left(1 / q_{m} \cdot b\right)$ and intercept $\left(1 / q_{m}\right)$ of the line. The values of $q_{m}, b$ and regression coefficient $\left(R^{2}\right)$ are listed in Table 1.

The essential characteristics of the Langmuir isotherm parameters can be used to predict the affinity between the biosorbate and biosorbent which is calculated using following equation;

$$
R_{L}=\frac{1}{1+b c_{i}}
$$

where $\mathrm{b}$ is the Langmuir constant and $C_{i}$ is the maximum initial concentration of chromium (VI). The value of separation parameters $R_{L}$ provides important information about the nature of adsorption. The value of $R_{L}$ indicated the type of Langmuir isotherm separation factor or dimensionless equilibrium parameters, $R_{L}$ expressed as in the following equation: to be irreversible $\left(R_{L}=0\right)$, favorable $\left(0<R_{L}<1\right)$, linear $\left(R_{L}=1\right)$ or unfavorable $\left(R_{L}>1\right)$. The $R_{L}$ was found to $0.2285-0.9367$ for concentration of $5 \mathrm{mg} / \mathrm{L}-$ $250 \mathrm{mg} / \mathrm{L}$ of chromium (VI). They are in the range of 0-1 which indicates favorable biosorption (Malkoc and Nuhoglu 2005).

Frenudlich adsorption isotherm (Frenudlich, 1939): Freundlich equation is represented by;

$$
q=K C_{e}^{1 / n}
$$

where $K$ and $n$ are empirical constants incorporating all parameters affecting the biosorption process such as, biosorption capacity and biosorption intensity respectively.

Linearized Freundlich adsorption isotherm was used to evaluate the sorption data and is represented as:

$$
\log q=\log K+\frac{1}{n} \log C_{e}
$$

Equilibrium data for the adsorption is plotted as $\log q$ vs $\log C_{e}$, as shown in Figure 10 (b). The two constants $n$ and $K$ are calculated from the slope $(1 / n)$ and intercept $(\log K)$ of the line, respectively. The values of $K, 1 / n$ and regression coefficient $\left(R^{2}\right)$ are listed in Table 1.

The $n$ value indicates the degree of non-linearity between solution concentration and adsorption as follows: if $\mathrm{n}=1$, then adsorption is linear; if $n<1$, then adsorption is chemical process; if $n>1$, then adsorption is a physical process. A relatively slight slope and a small value of $1 / n$ indicate that, the biosorption is good over entire range of concentration. The $n$ value in Freundlich equation was found to be 1.1900. Since $n>1$, this indicates that biosorption is a physical process biosorption of chromium (VI) ions onto calcium alginate immobilized banana peels. The higher value of $K$ (1.7202) indicates the higher adsorption capacity for the calcium alginate immobilized banana peels (Musa paradisiaca L.).

\section{Dubinin-Kaganer-Radushkevich}

(DKR) adsorption isotherm (Dubinin and Radushkevich, 1947):

Linearized Dubinin-Kaganer-Radushkevich (DKR) adsorption isotherm equation is represented as;

$$
\ln q_{e}=\ln q_{m}-\beta \varepsilon^{2}
$$

where $q_{m}$ is the maximum biosorption capacity, $\beta$ is the activity coefficient related to mean biosorption energy and $\varepsilon$ is the polanyi potential, which is calculated from the following relation;

$$
\varepsilon=R \operatorname{Tln}\left(1+\frac{1}{C_{e}}\right)
$$

Equilibrium data for the adsorption is plotted as $\ln q_{e}$ vs $\varepsilon^{2}$, as shown in Figure 10 (c). The two constants $\beta$ and $q_{m}$ are calculated from the slope $(\beta)$ and intercept $\left(\ln q_{m}\right)$ of the line, respectively. The values of adsorption energy $E$ was obtained by the following relationship,

$$
E=\frac{1}{\sqrt{-2 \beta}}
$$

The $\mathrm{E}$ value was found to be $0.7071 \mathrm{KJ} \mathrm{mol}^{-1}$. The mean free energy gives information about biosorption mechanism whether it is physical or chemical biosorption. If $E$ value lies between $8 \mathrm{KJ} \mathrm{mol}^{-1}$ and 16 
$\mathrm{KJ} \mathrm{mol}^{-1}$, the biosorption process take place chemically and $E>8 \mathrm{KJ} \mathrm{mol}^{-1}$, the biosorption process of the physical in nature (Olivieri and Brittenham, 1997). In the present work, $E$ value $\left(0.7071 \mathrm{KJ} \mathrm{mol}^{-1}\right)$ which is less than $8 \mathrm{KJ} \mathrm{mol}^{-1}$, the biosorption of chromium (VI) ions onto calcium alginate immobilized banana peels (Musa paradisiaca L.) is of physical in nature (Sawalha et al., 2006).

Temkin adsorption isotherm (Temkin and Pyzhev, 1940):

Linearized Temkin adsorption isotherm is given by the equation;

$$
q_{e}=\frac{R T}{b_{T}} \ln A_{T}+\frac{R T}{b_{T}} \ln C_{e}
$$

where $b_{T}$ is the Temkin constant related to heat of biosorption $(\mathrm{J} / \mathrm{mol})$ and $A_{T}$ is the Temkin isotherm constant $(\mathrm{L} / \mathrm{g})$. Equilibrium data for the adsorption is plotted as $q_{e}$ vs $\ln C_{e}$, as shown in Figure $10(\mathrm{~d})$. The two constants $b_{T}$ and $A_{T}$ are calculated from the slope $\left(R T / b_{T}\right)$ and intercept $\left(R T / b_{T} \cdot \ln A_{T}\right)$ of the line. The values of $A_{T}, b_{T}$ and regression coefficient $\left(R^{2}\right)$.

The various constants and regression coefficient $R^{2}$ obtained from adsorption isotherms (Langmuir, Freundlich, Dubinin-Kaganer-Redushkevich (DKR) and Temkin) are summarized in Table 1.

\section{Adsorption kinetics:}

As aforementioned, a lumped analysis of adsorption rate is sufficient to practical operation from a system design point of view. The commonly employed lumped kinetic models, namely (a) the pseudo-firstorder equation (Lagergren 1898) (b) the pseudosecond-order equation (Mckay et al., 1999) (c) Elovich equation (Chien and Clayton 1980) (d) Weber $\&$ Morris intra-particle diffusion equation (Weber and Morris, 1963) are presented below;

$$
\begin{aligned}
& \ln \left(q_{e}-q_{t}\right)=\ln q_{e}-k_{1} t \\
& \frac{t}{q_{t}}=\frac{1}{k_{2} q_{e}^{2}}+\frac{t}{q_{e}} \\
& q_{t}=\frac{1}{\beta} \ln (\alpha \beta)+\frac{1}{\beta} \ln t \\
& q_{t}=k_{i} t^{0.5}+c
\end{aligned}
$$

where $q_{e}\left(\mathrm{mg} \mathrm{g}^{-1}\right)$ is the solid phase concentration at equilibrium, $q_{t}\left(\mathrm{mg} \mathrm{g}^{-1}\right)$ is the average solid phase concentration at time $t(\mathrm{~min}), k_{1}\left(\mathrm{~min}^{-1}\right)$ and $k_{2}\left(\mathrm{~g} \mathrm{mg}^{-1}\right.$ $\mathrm{min}^{-1}$ ) are the pseudo-first-order and pseudo-secondorder rate constants, respectively. The symbols of $\alpha$ $\left(\mathrm{mg} \mathrm{g}^{-1} \mathrm{~min}^{-1}\right)$ and $\beta\left(\mathrm{g} \mathrm{mg}^{-1}\right)$ are Elovich coefficients representing initial biosorption rate and desorption constants, respectively. $k_{i}\left(\mathrm{mg} \mathrm{g}^{-1} \mathrm{~min}^{-1 / 2}\right)$ is the intraparticle diffusion rate constant, $c$ is intercept.

If the adsorption follows the pseudo-first-order model, a plot of $\ln \left(q_{e}-q_{t}\right)$ against time $t$ should be a straight line. Similarly, $t / q_{t}$ should change lineally with time $t$ if the adsorption process obeys the pseudo-second order model. If the adsorption process obeys Elovich model, a plot of $q_{t}$ against $\ln t$ should be a straight line. Also a plot of $q_{t}$ against $t^{0.5}$ changes lineally the adsorption process obeys the Weber and Morris intraparticle diffusion model. Kinetic plots depicted in Figure 8 (a) (b) (c) and (d) (Septhum et al., 2007).

Biosorption of chromium (VI) onto biosorbent was monitored at different specific time interval. The chromium (VI) uptake was calculated from the data obtained. From the chromium (VI) uptake was plotted against time to determine a suitable kinetic model, the adsorption data was fitted into pseudo-first-order model, pseudo-second-order model, Elovich models and the Weber \& Morris intra-particle diffusion model.

The pseudo-first-order model was plotted for $\ln \left(q_{e}-q_{t}\right)$ against $\mathrm{t}$ (Figure 11 (a)). The values of $k_{l}$ and $q_{e}$ values were calculated from the slope $\left(k_{1}\right)$ and intercept $\left(\ln q_{e}\right)$ of the plot and shown in Table 2 . Pseudo-first-order model showered the correlation value $\left(R^{2}=0.9418\right)$ being lower than the correlation coefficient for the pseudo-second-order model. Kinetic biosorption for pseudo-first-order model occurs chemically and involves valency forces through ion sharing or exchange of electron between the biosorbent and the ions adsorbed onto it (Septhum et al., 2007).

The pseudo-second-order model was plotted for $t / q_{t}$ against $\mathrm{t}$ (Figure 11 (b)). The values of $q_{e}$ and $k_{2}$ are calculated from the slope $\left(1 / q_{e}\right)$ and intercept $\left(1 / k_{2}\right.$ $q_{e}{ }^{2}$ ) of the plot and values are shown in Table 2 . Pseudo-second-order kinetic model showered the strongest correlation $\left(R^{2}=0.9606\right)$. This suggests that chromium (VI) biosorption occurs in a monolayer fashion and which relies on the assumption that chemisorption or chemical adsorption is the ratelimiting step. Chromium (VI) reacts chemically with the specific binding sites on the surface of biosorbent.

The Elovich model was plotted for $q_{t}$ against $\ln t$ (Figure 11 (c)). The values of $\beta$ and $\alpha$ are calculated from the slope $(1 / \beta)$ and the intercept $(\ln (\alpha \beta) / \beta)$ of 
the plot and values are shown in Table 2. The Elovich model has been used with the assumption that the actual adsorption surface is energetically heterogeneous (Thomas and Thomas, 1997).

The Weber \& Morris intra-particle diffusion model was plotted for $q_{t}$ against $t^{0.5}$ (Figure $11(\mathrm{~d})$ ). The value of $k_{i}$ and $c$ are calculated from the slope $\left(k_{i}\right)$ and intercept $(c)$ of the plot and values are shown in Table 2. The Weber and Morris intra-particle diffusion model showed a $\left(R^{2}=0.9587\right)$ being lower than the correlation coefficient for the pseudo-second-order model. The intercept of the plot does not pass through the origin, this is indicative of some degree of boundary layer control and intra-particle pore diffusion is not only rate-limiting step (Weber and Morris, 1963).

The plot of intra-particle diffusion model showed multilinearity, indicating that three steps take place. The first, sharper portion is attributed to the diffusion of adsorbate through the solution to the external surface of biosorbent or the boundary layer diffusion of solute molecules. The second portion describes ion stage, where intra-particle diffusion is a rate limiting. The third portion is attributed to the final equilibrium stage. However the intercept of the line fails to pass through the origin which may attribute to the difference in the rate of mass transfer in the initial and final stages of biosorption (Panday et al., 1986).

\section{Determination of thermodynamic}

The effect of temperature on removal of chromium (VI) from aqueous solutions in the concentration of chromium (VI) $10 \mathrm{mg} / \mathrm{L}$ and biosorbent dose concentration $5 \mathrm{mg} / \mathrm{ml}$ with optimum $\mathrm{pH} 4.0$ was studied. Experiments were carried out at different temperatures from $20^{\circ} \mathrm{C}-40^{\circ} \mathrm{C}$. The samples were allowed to attain equilibrium. Sorption slightly increases from. The equilibrium constant (Catena and Bright, 1989) at various temperatures and thermodynamic parameters of adsorption can be evaluated from the following equations;

$$
\begin{gathered}
K_{c}=\frac{C_{A e}}{C_{e}} \\
\Delta G^{0}=-R T \ln K_{c} \\
\Delta G^{0}=\Delta H^{0}-T \Delta S^{0} \\
\ln K_{c}=\frac{\Delta S^{0}}{R}-\frac{\Delta H^{0}}{R T}
\end{gathered}
$$

where $K_{c}$ is the equilibrium constant, $C_{e}$ is the equilibrium concentration in solution $(\mathrm{mg} / \mathrm{L})$ and $C_{A e}$ is the amount of chromium (VI) biosorbed on the biosorbent per liter of solution at equilibrium $(\mathrm{mg} / \mathrm{L})$. $\Delta G^{0}, \Delta H^{0}$ and $\Delta S^{0}$ are changes in standard Gibbs free energy $(\mathrm{kJ} / \mathrm{mol})$, standard enthalpy $(\mathrm{kJ} / \mathrm{mol})$ and standard entropy $(\mathrm{J} / \mathrm{mol} \mathrm{K})$, respectively. $R$ is the gas constant $(8.314 \mathrm{~J} / \mathrm{mol} \mathrm{K})$ and $\mathrm{T}$ is the temperature $(\mathrm{K})$.

The values of $\Delta H^{0}$ and $\Delta S^{0}$ were determined from the slope and the intercept from the plot of $\ln K c$ versus $1 / T$ (Figure 12). The values of equilibrium constant $(K c)$, standard Gibbs free energy change $\left(\Delta G^{0}\right)$, standard enthalpy change $\left(\Delta \mathrm{H}^{0}\right)$ and the standard entropy change $\left(\Delta S^{0}\right)$ calculated in this work were presented in Table 3 . The equilibrium constant $(K c)$ increases with increase in temperature, which may be attributed to the increase in the pore size and enhanced rate of intra-particle diffusion. The value of standard Gibbs free energy change $\left(\Delta G^{0}\right)$ is small and negative and indicates the spontaneous nature of the biosorption. The values of $\Delta G^{0}$ were found to decreases as the temperature increases, indicating more driving force and hence resulting in higher biosorption capacity. The value of $\Delta H^{0}$ was positive, indicating the endothermic nature of the biosorption of chromium (VI) onto calcium alginate immobilized banana peels (Musa paradisiaca L.). The positive values of $\Delta S^{0}$ shows an affinity of biosorbent and the increasing randomness at the solid solution interface during the biosorption process.

\section{CONCLUSIONS}

The present investigation revealed that calcium alginate immobilized banana peels (Musa paradisiaca L.) used as inexpensive, excellent biosorbent for the removal of chromium (VI) from aqueous solutions. The optimal parameters such as solution $\mathrm{pH}$, biosorbent dose, initial chromium (VI) concentration, contact time temperature and agitation rate determined in the experiment were effective in determining the efficiency of chromium (VI) biosorption onto calcium alginate immobilized banana peels (Musa paradisiaca L.). Biosorption equilibrium exhibited better fit to Langmuir isotherm than Freundlich isotherm, Temkin isotherm and DubininKaganer-Redushkevich (DKR) isotherm. The maximum chromium (VI) loading capacity $\left(q_{e}\right)$ of calcium alginate immobilized banana peels (Musa paradisiaca L.) determined from Langmuir adsorption isotherm was found to be $109.890 \mathrm{mg} \mathrm{g}^{-1}$. The 
Pseudo-second-order model was found to be correlate the experimental data strongest than other three kinetic models. The thermodynamic study confirmed that reaction of biosorption of chromium (VI) was spontaneous, endothermic and increasing randomness of the solid solution interfaces. From these observations it can be concluded that calcium alginate immobilized banana peels (Musa paradisiaca L.) has considerable biosorption capacity, available in abundant, non-hazardous agro material can be used as an effective indigenous material for treatment of wastewater stream containing chromium (VI).

\section{ACKNOWLEDGEMENTS:}

The authors are thankful to Principal Dr. Sam Sakaria for their administrative support, cooperation and help. Thanks to IIT Bombay for the testing the samples using an Inductively Coupled Plasma - Atomic Emission Spectroscopy (ICP-AES) and Scanning Electron Microscope (SEM). Also, special thanks to VIVA College and Institute of Science for the Fourier Transform Infrared (FTIR) and X-ray diffraction (XRD) analysis respectively.

\section{REFERENCES}

1. Sharma, A., Maind, S.D. and Bhalerao, S.A., 2015. Studies on Cr (VI) biosorption using cost effective biosorbent: peanut hulls (Arachis hypogaea Linn.). Asian Journal of Science and Technology. 6(5), 1425-1435.

2. Bhalerao, S.A., 2011. Biosorption an eco-friendly cost effective technology of removal of heavy metals an overview. Bionano Frontier special Issue. 6, 219-225.

3. Dubinin, M.M. and Radushkevich, L.V., 1947. Equation of the characteristic curve of activated charcoal, Proc. Academy of Sci. Phy. Chem. Section, U.S.S.R. 55, 331-333.

4. Freundlich, H.M.F., 1906.Uber dies adsorption in losungen, Zeitschriftue Physikalische Chemie (Leipzig). A57, 385-470.

5. Langmuir, I., 1918. The adsorption of gases on plane surface of glass, mica and platinum, J. Am. Chem. Soc. 40, 1361-1403.

6. Temkin, M.J. and Pyzhev, V., 1940. Kinetics of ammonia synthesis on promoted iron catalysts. ActaPhysiochim. Urrs. 12, 217-222.

7. Lagergren, S., 1898. About the theory of so-called adsorption of soluble substances, Kungliga Svenska Vetenskapsakadeimens Handlingar. 24, 1-39.
8. McKay, G., Ho, Y.S. and Ng, J.C.Y., 1999. Biosorption of copper from waste waters: A review, Sep. Purif. Methi. 28, 87-125.

9. Weber, W. J. and Morris, J.C., 1963. Kinetics of adsorption on carbon solution. J. Sanit. Eng. Div. Am. Soc. Civ. Engg. 89, 31-59.

10. Gadd, G. M., 1992.Metals and microorganisms: a problem of definition. FEMS Microbiol Lett. 100, 197-204.

11. Septhum, C., Rattanaphani, S., Bremner, J. B. and Rattanaphani, V., 2007. An adsorption of Al (III) ions onto chitosan. J. Hazardous Materials. 148, 185-191.

12. Veglio, F. and Beolchini, F., 1997. Removal of heavy metals by biosorption: A review. Hydrometallurgy. 44, 301-316.

13. Volesky, B., 2001. Detoxification of metalbearing effluents: biosorption for the next century. Hydrometallururgy. 59 (2-3), 203-216.

14. Prakasham R.S., Merrie J.S., Sheela R., Saswathi N. and Ramakrishana S.V., 1999, Biosorption of chromium (VI) by free and immobilized Rhizopus arrhizus. Environmental Pollution, 104, 421-427.

15. Chien S. H. and Clayton W. R., (1980). Application of Elovich equation to the kinetics of phosphate release and sorption in soils, Soil Sci. Soc. Am. J., 44, 265-268.

16. Bhatti H. N., Nasir A. W., and Hanif M. A., 2010. Efficacy of Daucus carota L. waste biomass for the removal of chromium from aqueous solutions. Desalination, 253 (1-3). 78-87.

17. Sharmila S., Rebecca L. J., and Saduzzaman M., (2012). Immobilization of plant protease using calcium alginate beads. Journal of Chemical and Pharmaceutical Research, 4 (10), 4484-4488.

18. Rao P. S., Shashikant R. and Munjunatha G.S., 1992. Kinetic studies on adsorption of chromium by coconut shell carbons from synthetic effluents. J. Environ. Sci. Health, 27, 2227-2241.

19. Karthikeyan S., Balasubramanian R. and Iyer C. S. P., 2007. Evaluation of marine algae Uiva fasciata and Sargassum sp. for biosorption of $\mathrm{Cu}$ (II) from aqueous solutions. Bioresour. Technol., 98 (2), 452-455.

20. Thomas, J. M. and Thomas, W. J., (1997). Principle and Practice of heterogeneous catalysis, weinheim, VCH.

21. Malkoc E. and Nuhoglu Y. J., (2005). Investigation of Nickel (II) removal from aqueous solutions using tea factory waste, J. Hazard. Mater, B127, 120-128. 
22. Olivieri N. F. and Brittenham G. M., (1997). Ironchelating therapy and the treatment of thalassemia. Blood, 89, 739-761.

23. Sawalha, M. F. and Peralta-Videa, J. R., RomeroGonzalez, J. and Gardea-Torresdey, J. L., (2006). Biosorption of $\mathrm{Cd}$ (II), Cr (III) and Cr (VI) by saltbush (Atriplex canescens) biomass: Thermodynamic and isotherm studies, J. Colloid Interface Sci., 300, 100-104.

24. Catena G. C. and Bright F. V., (1989). Thermodynamic study on the effect of cyclodixtrin inclusion with aniline naphthalene sulphonates. Anal. Chem., 61, 905-909.

25. Panday K. K., Prasad G. and Singh V. N., (1986). Mixed adsorbents for $\mathrm{Cu}$ (II) removal from aqueous solutions. Environ. Technol. Lett., 50, 547-550.

26. Naiya T. K., Das S. K. and Bhattacharya A. K., (2009). Adsorption of $\mathrm{Cd}$ (II) \& $\mathrm{Pb}$ (II) from aqueous solution on activated alumina. J. Coll. Inter. Sci., 21, 434-451.

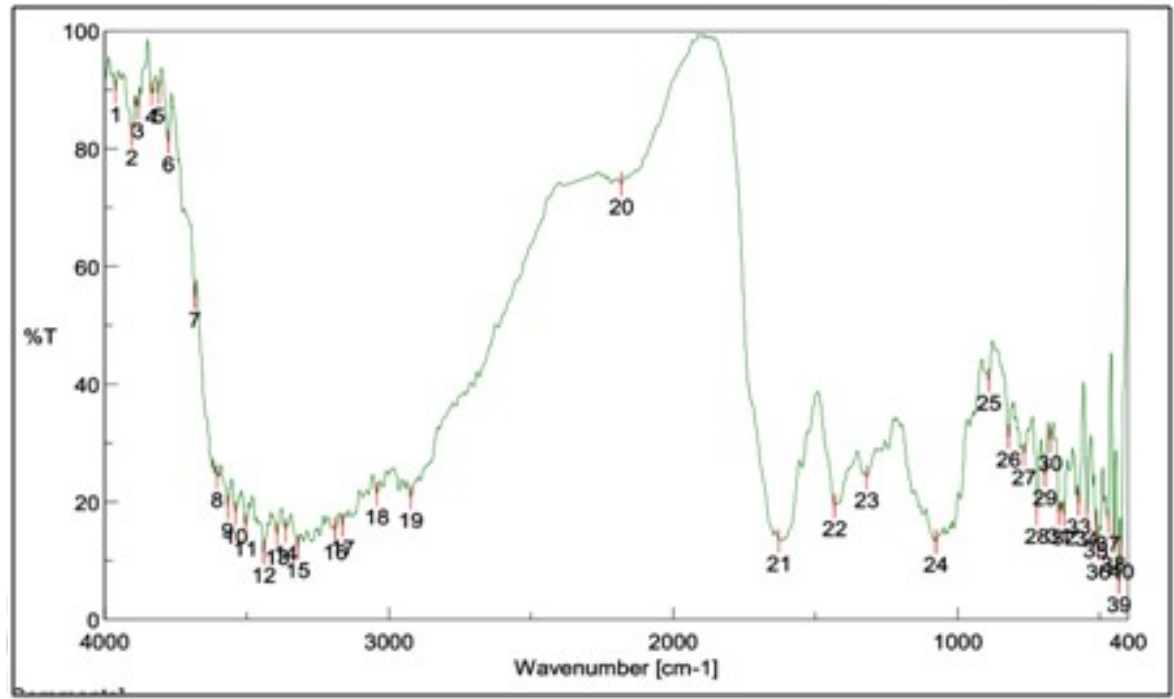

(a)

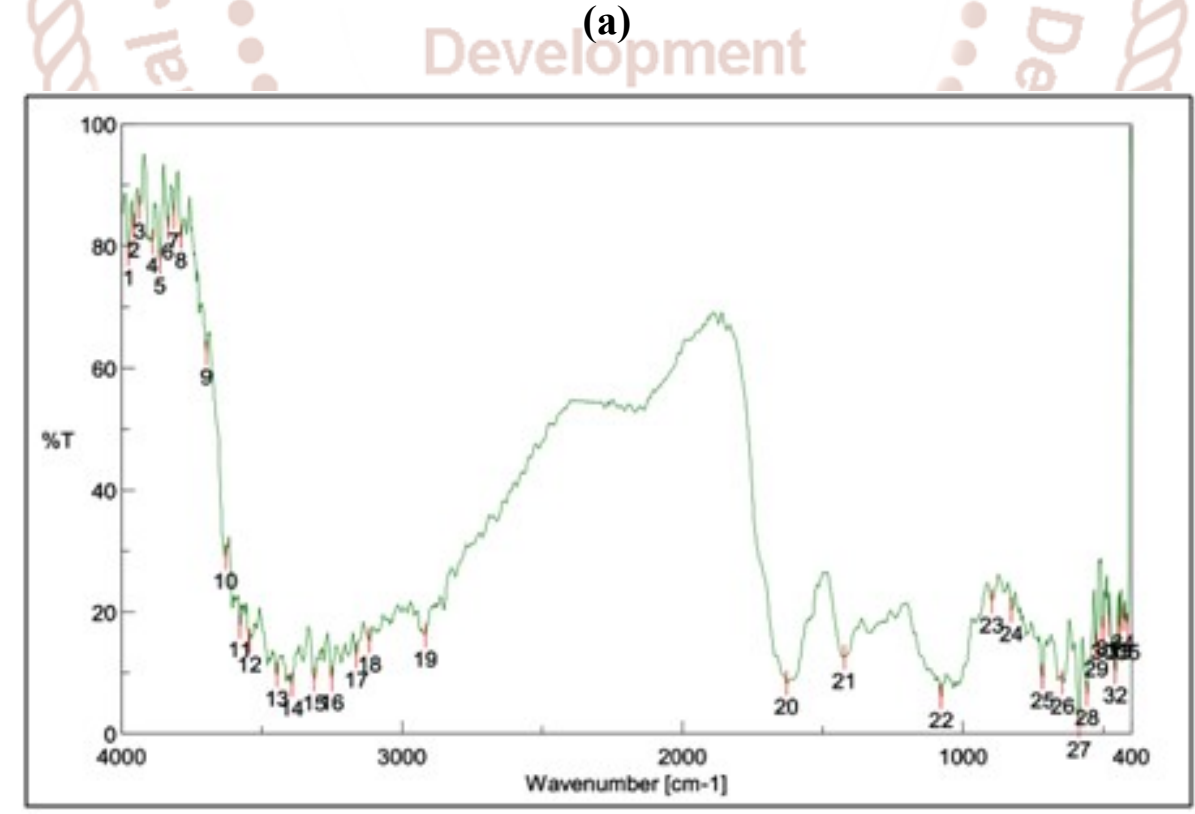

(b)

Figure 1: FTIR spectra of calcium alginate immobilized banana peels (Musa paradisiaca L.)(a) Unloaded with chromium (VI) (b) Loaded with chromium (VI) 


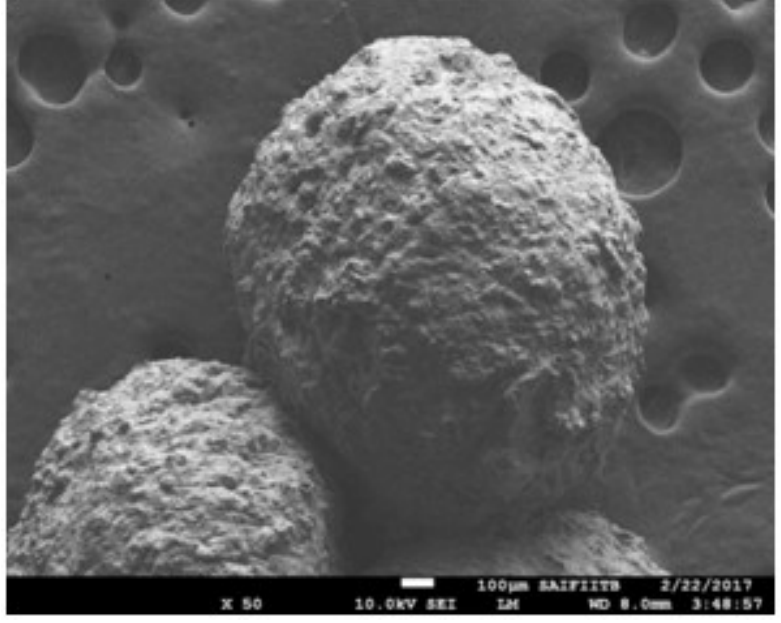

(a)

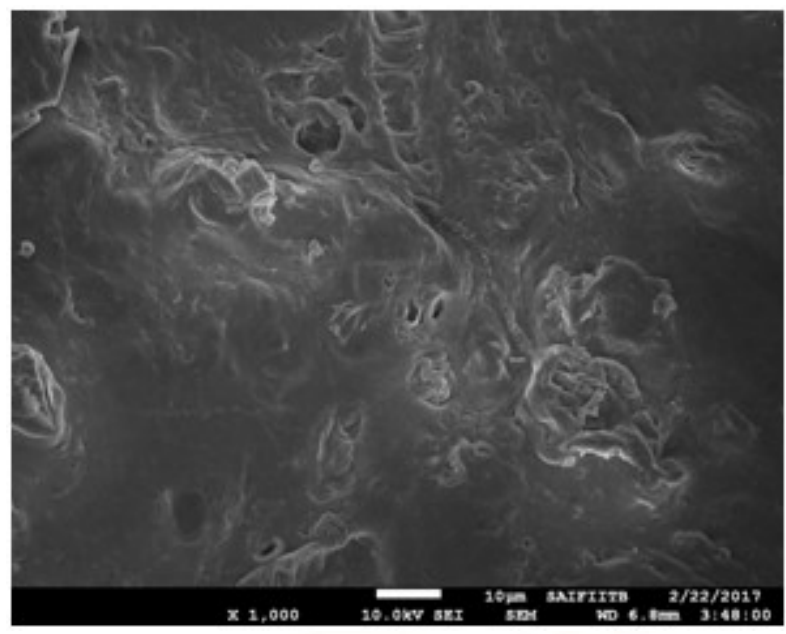

(b)

Figure 2: Scanning Electron Microscope (SEM) analysis of calcium alginate immobilized banana peels (Musa paradisiaca L.) (a) Unloaded with chromium (VI) (b) Loaded with chromium (VI)

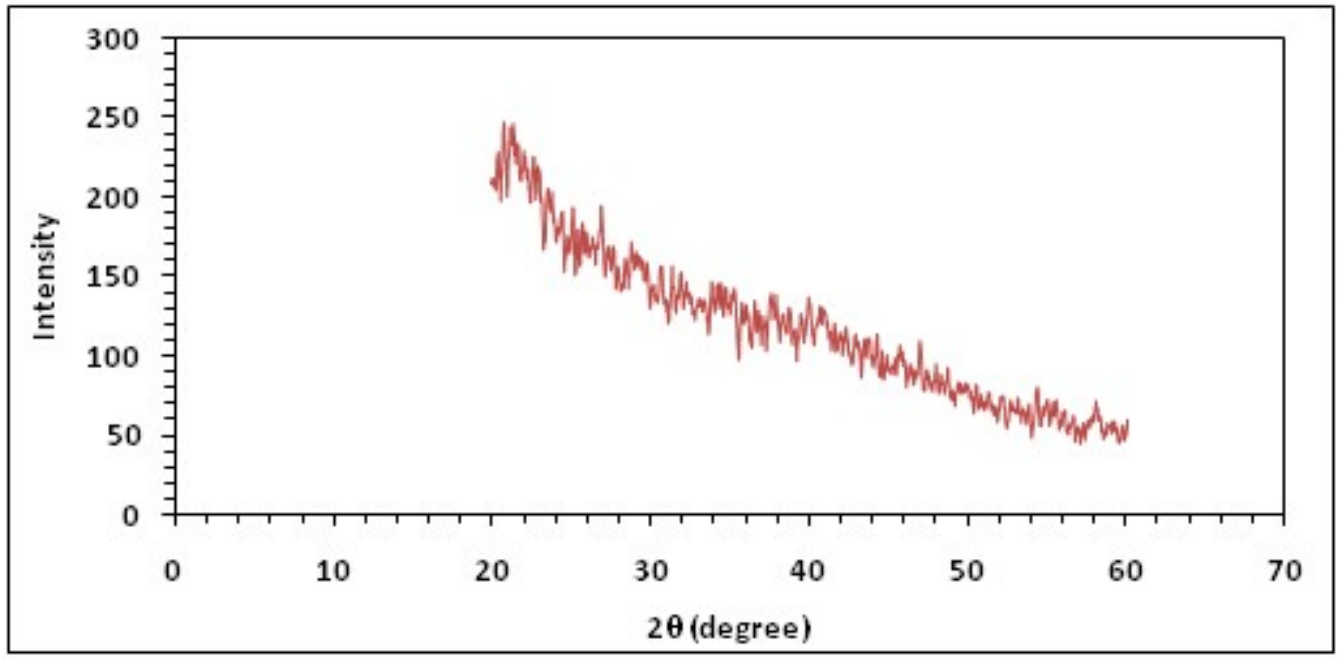

(a)

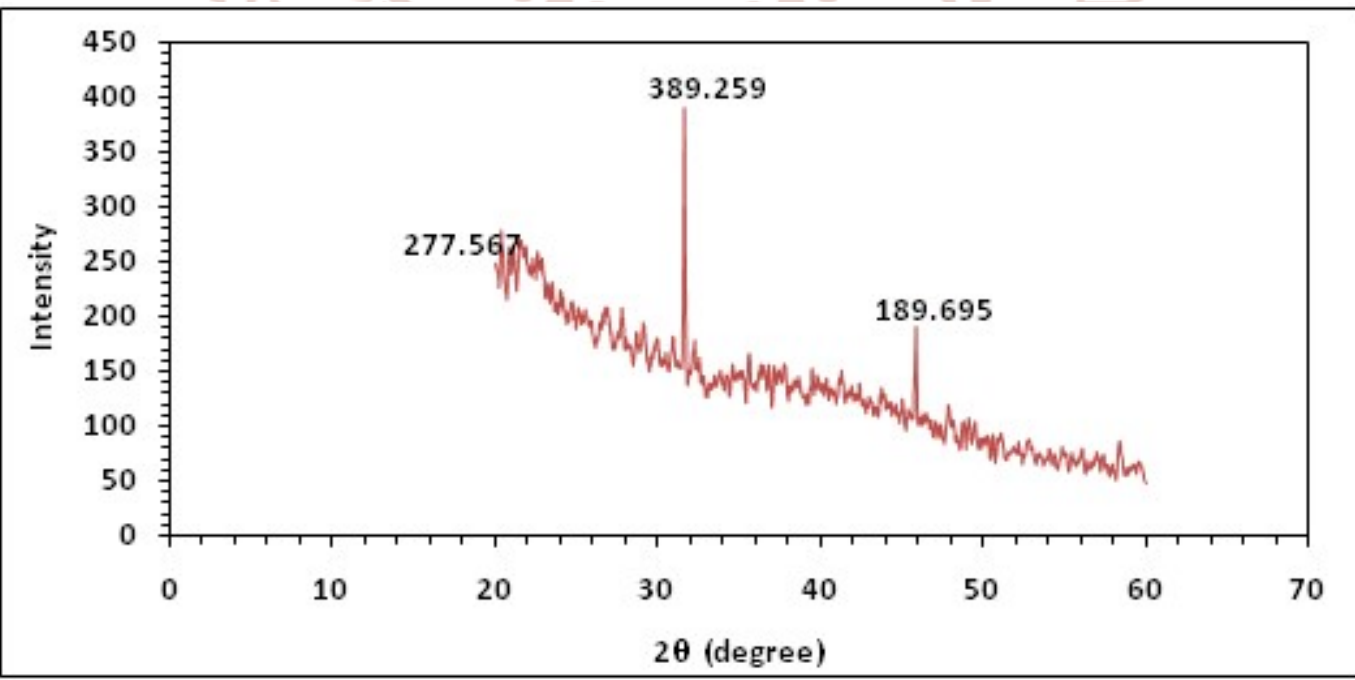

(b)

Figure 3:X-ray diffraction (XRD) analysis of calcium alginate immobilized banana peels (Musa paradisiaca L.)(a) Unloaded with chromium (VI) (b) Loaded with chromium (VI) 


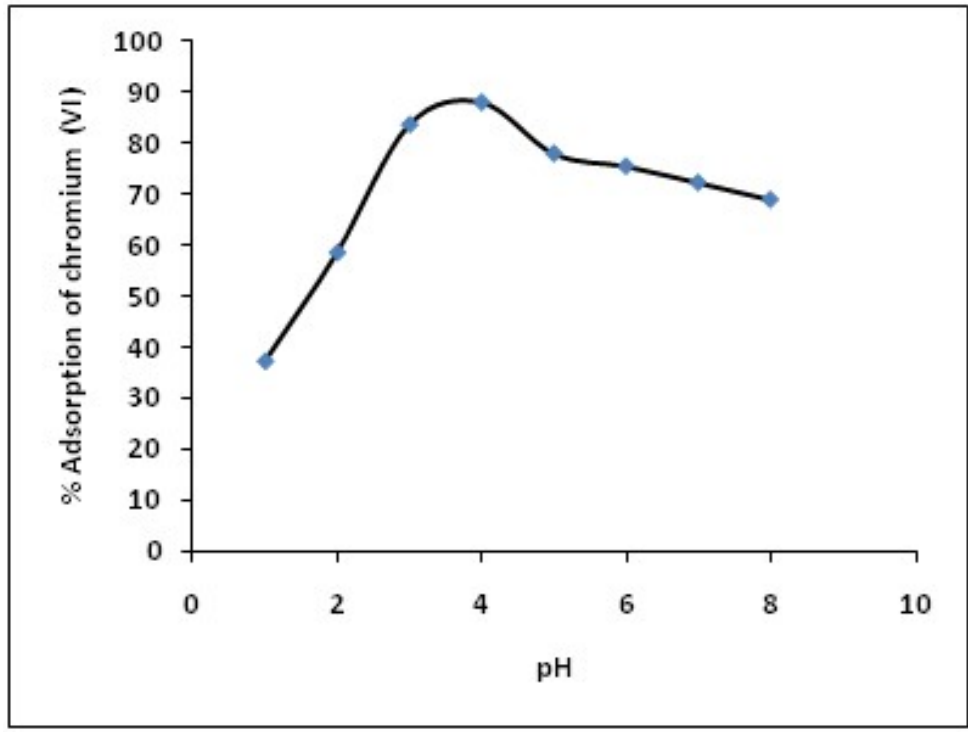

Figure 4: Effect of pH on chromium (VI) biosorption by calcium alginate immobilized banana peels (Musa paradisiaca L.) (biosorbent dose concentration: $5 \mathrm{~g} / \mathrm{L}$, chromium (VI) concentration: $10 \mathrm{mg} / \mathrm{L}$, contact time: 180 minutes, temperature: $30^{\circ} \mathrm{C}$ )

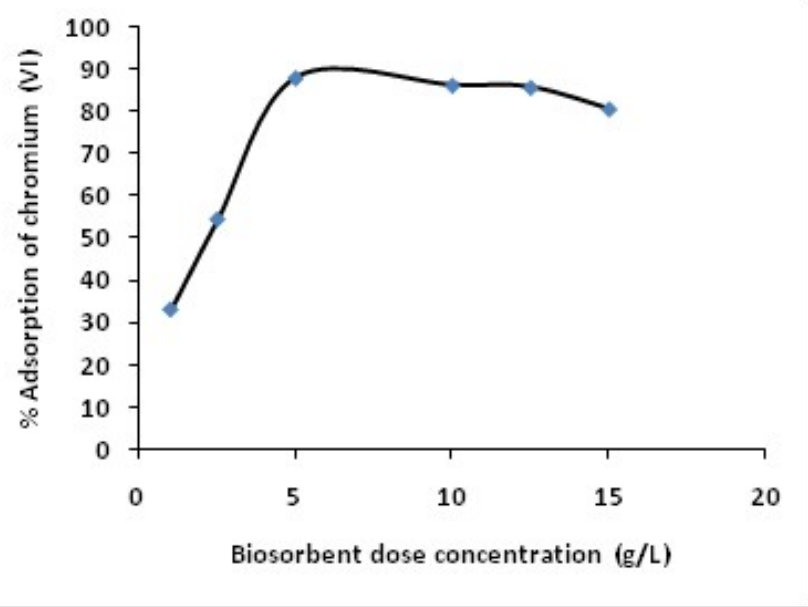

Figure 5: Effect of biosorbent dose concentration on chromium (VI) biosorption by calcium alginate immobilized banana peels (Musa paradisiaca L.) (pH: 4, chromium (VI) concentration: $10 \mathrm{mg} / \mathrm{L}$, contact time: 180 minutes, temperature: $30^{\circ} \mathrm{C}$ )

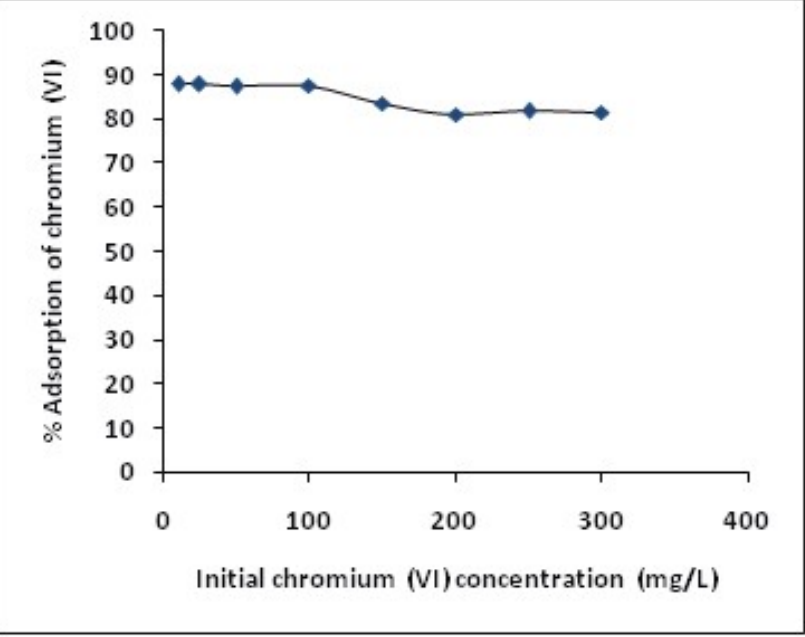

Figure 6: Effect of chromium (VI) concentration on chromium (VI) biosorption by calcium alginate immobilized banana peels (Musa paradisiaca L.) (pH: 4, biosorbent dose concentration: 5 g/L, contact time: 180 minutes, temperature: $30^{\circ} \mathrm{C}$ ) 


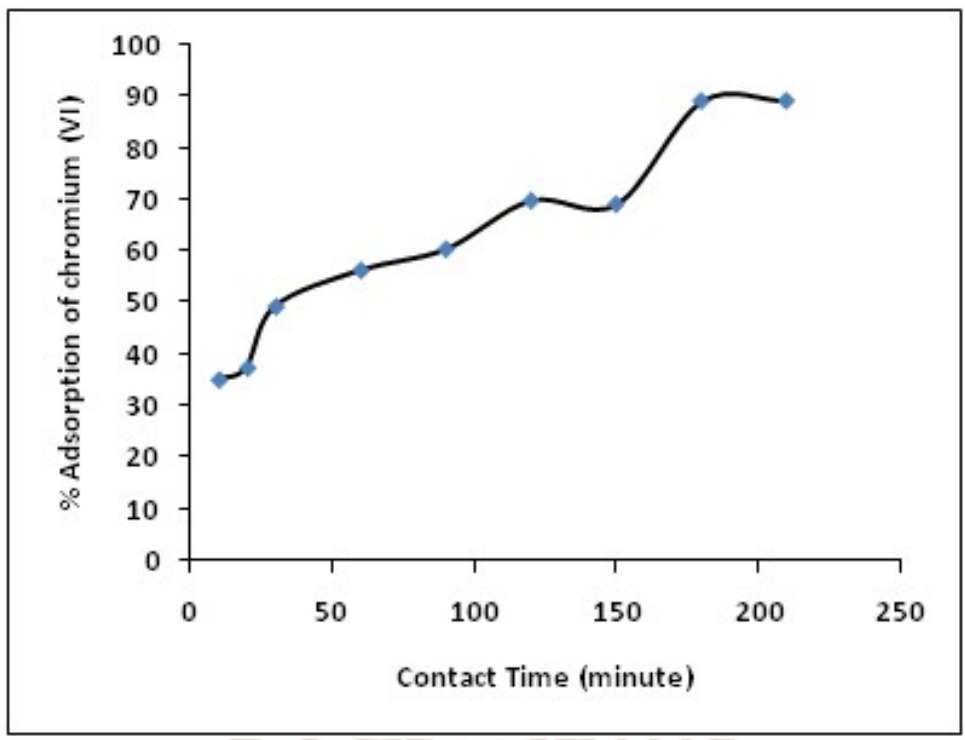

Figure 7: Effect of contact time on chromium (VI) biosorption by calcium alginate immobilized banana peels (Musa paradisiaca L.) (pH: 4, biosorbent dose concentration: $5 \mathrm{~g} / \mathrm{L}$, initial chromium (VI) concentration: $10 \mathrm{mg} / \mathrm{ml}$, temperature: $30^{\circ} \mathrm{C}$ )

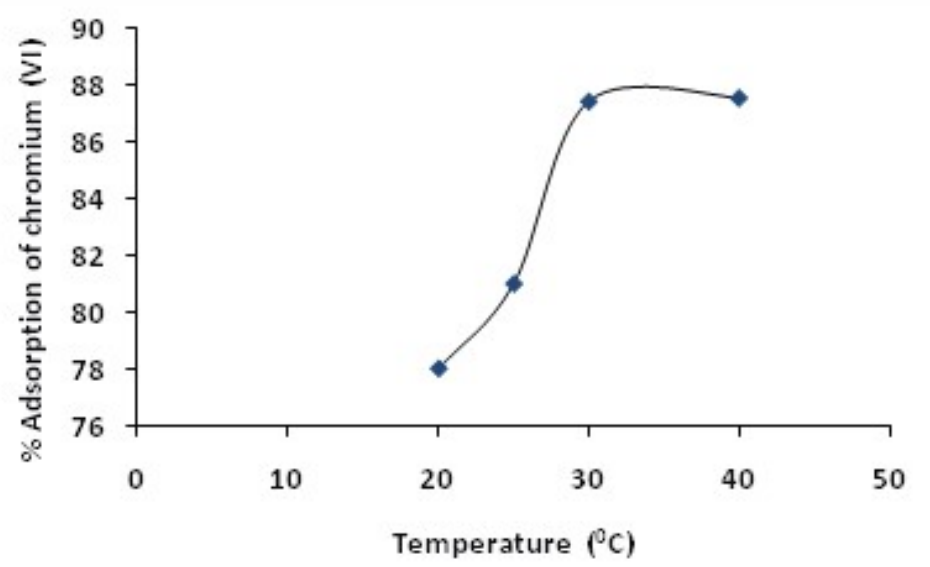

Figure 8: Effect of temperature on chromium (VI) biosorption by calcium alginate immobilized banana peels (Musa paradisiaca L.) (pH 4, biosorbent dose concentration: $5 \mathrm{~g} / \mathrm{L}$, initial chromium (VI) ions concentration: $10 \mathrm{mg} / \mathrm{L}$, contact time: 180 minutes)

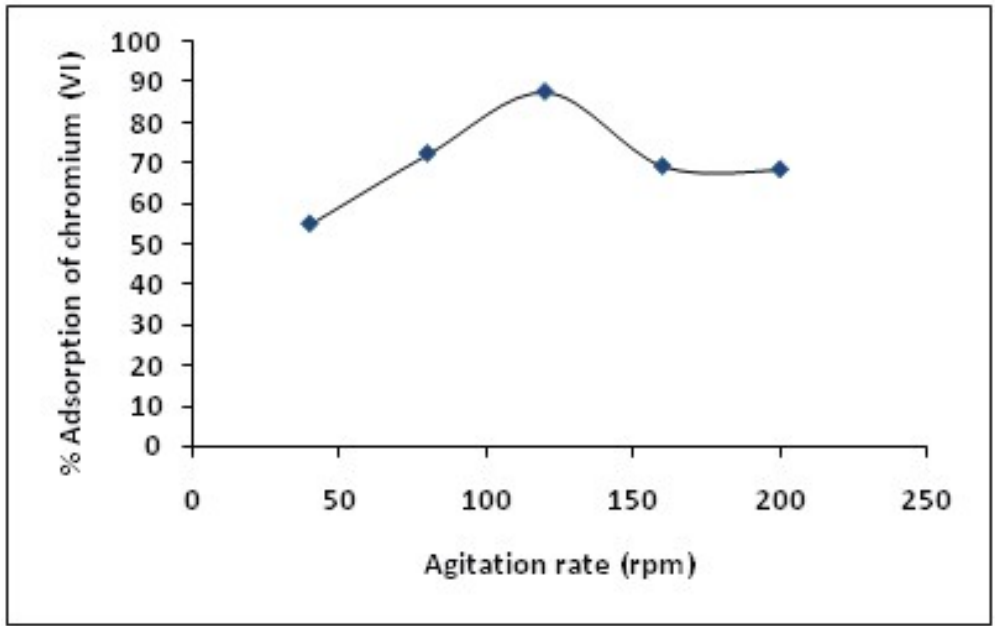

Figure 9: Effect of agitation rate on chromium (VI) biosorption by calcium alginate immobilized banana peels (Musa paradisiaca L.) (pH 4, biosorbent dose concentration: $5 \mathrm{~g} / \mathrm{L}$, initial chromium (VI) ions concentration: $10 \mathrm{mg} / \mathrm{L}$, contact time: 180 minutes, temperature: $30^{\circ} \mathrm{C}$ ) 
International Journal of Trend in Scientific Research and Development (IJTSRD) ISSN: 2456-6470

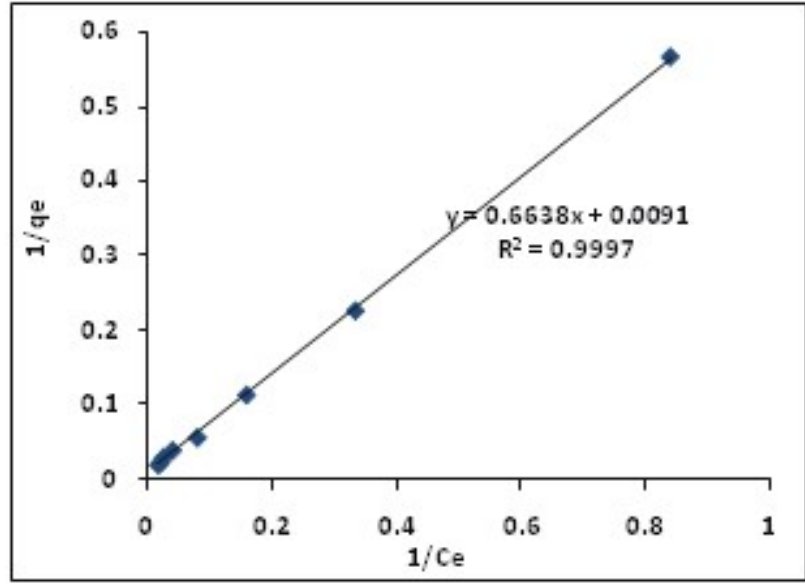

(a)

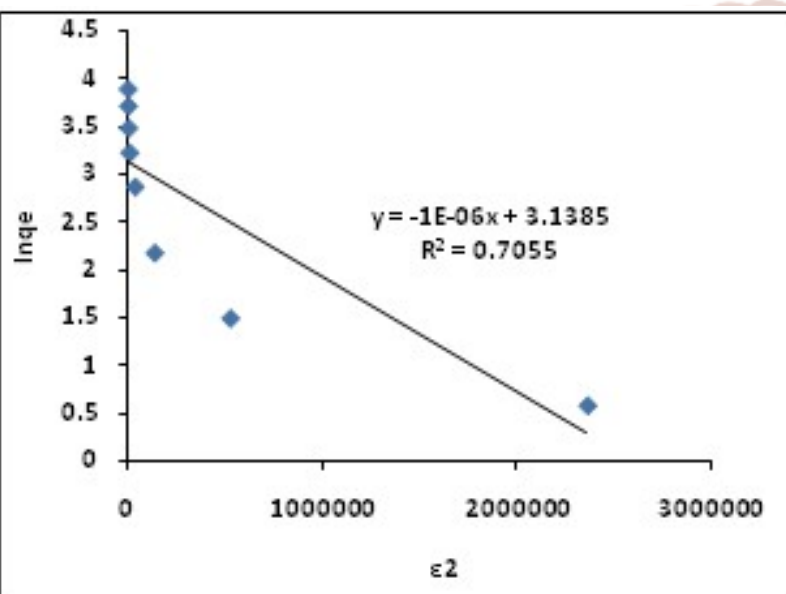

(c)

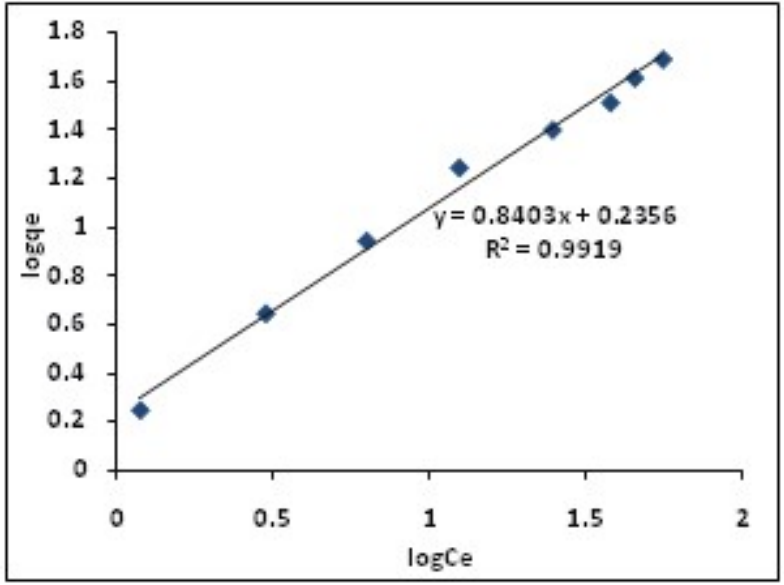

(b)

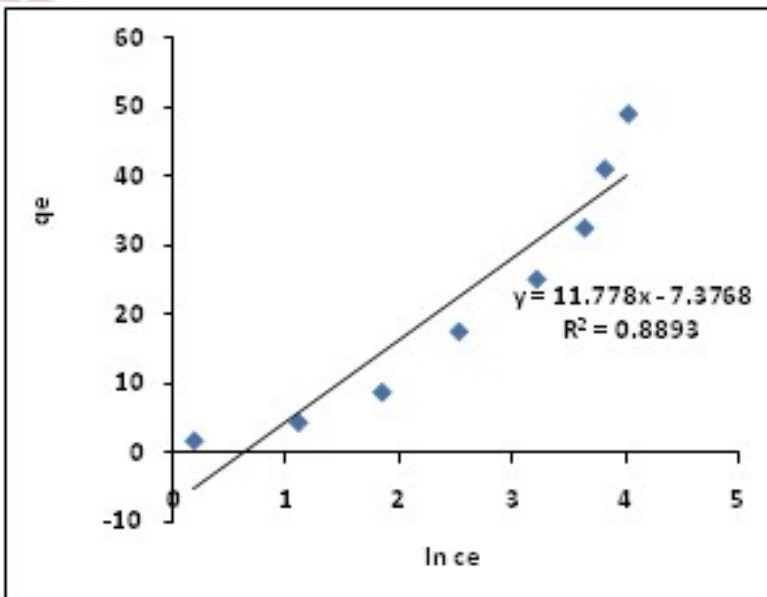

(d)

Figure 10: Adsorption isotherms (a) Langmuir, (b) Freundlich (c) DKR and (d) Temkin for chromium (VI) bisorption by calcium alginate immobilized banana peels (Musa paradisiaca L.) (pH: 4.0, biosorbent dose concentration: $5 \mathrm{~g} / \mathrm{L}$, contact time: 180 minutes, temperature: $30^{\circ} \mathrm{C}$ )

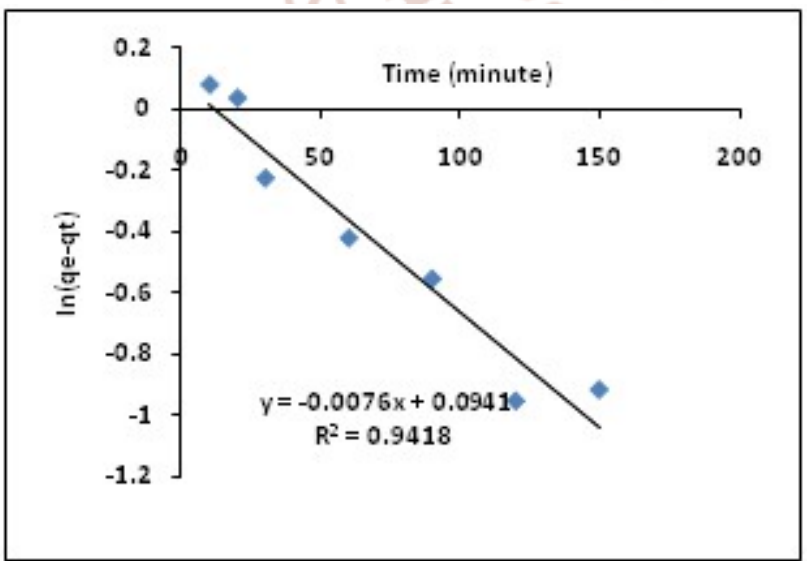

(a)

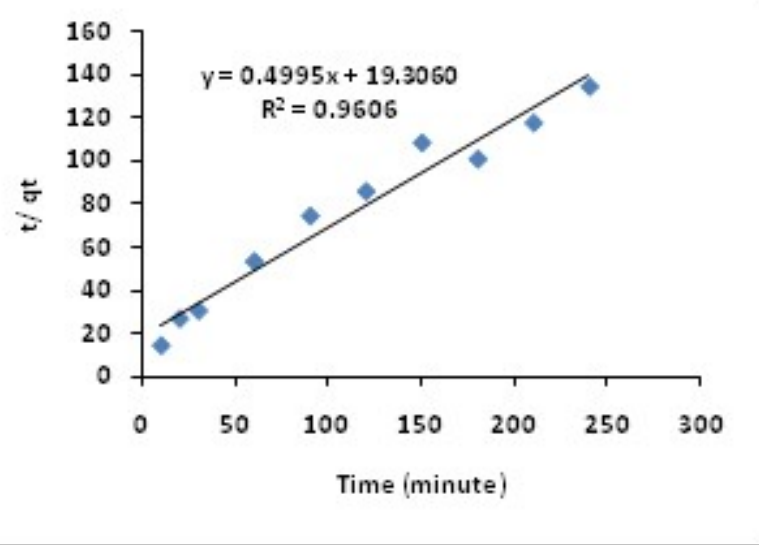

(b) 


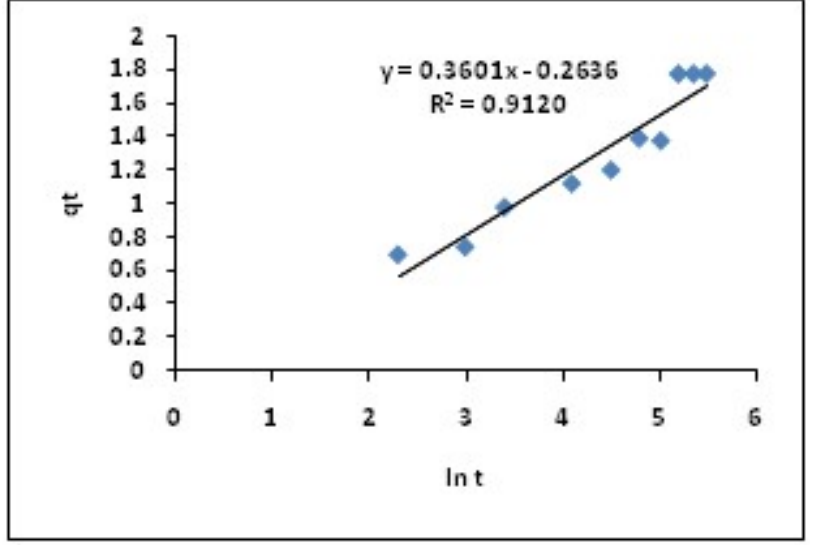

(c)

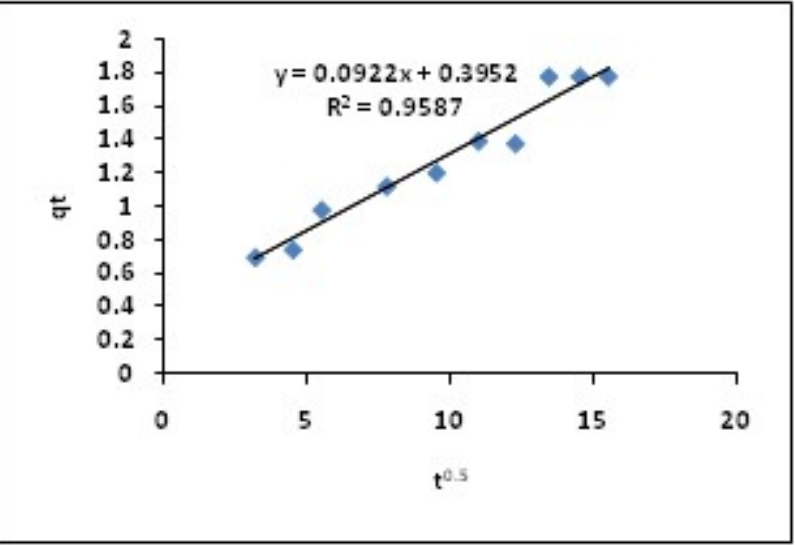

(d)

Figure 11: Adsorption kinetic models (a) pseudo-first-order, (b) pseudo-second-order (c) Elovich and (d)

Weber and Morris intra-particle diffussion equation, for biosorption of chromium (VI) by calcium alginate immobilized banana peels (Musa paradisiaca $\mathrm{L}$.) (pH: 4.0, biosorbent dose concentration: $5 \mathrm{~g} / \mathrm{L}$, initial chromium (VI) concentration: $10 \mathrm{mg} / \mathrm{L}$, temperature: $30^{\circ} \mathrm{C}$ )

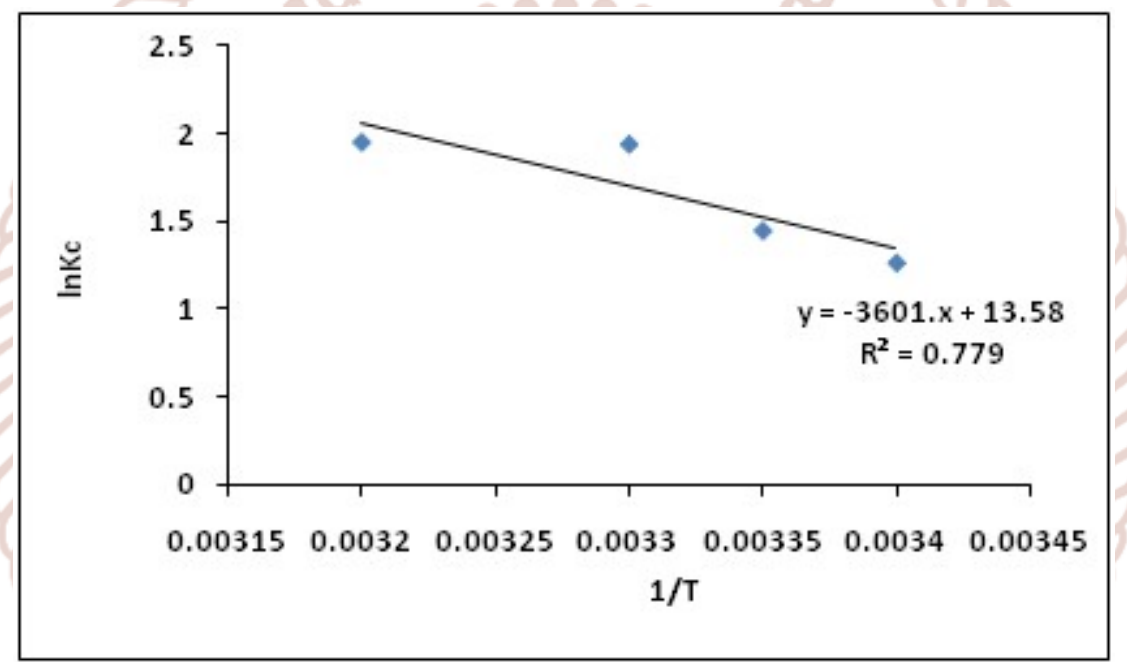

Figure 12: Plot of $\ln K c$ against $1 / T$ for determination of thermodynamic parameters for chromium (VI) biosorption by calcium alginate immobilized banana peels (Musa paradisiaca $\mathrm{L}$.) (pH: 4.0, biosorbent dose concentration: $5 \mathrm{~g} / \mathrm{L}$, chromium (VI) concentration: $10 \mathrm{mg} / \mathrm{L}$, contact time: 180 minutes)

Table 1: Adsorption isotherm constants for chromium (VI) bisorption by calcium alginate immobilized banana peels (Musa paradisiaca $\mathrm{L}$.)

\begin{tabular}{|c|c|c|c|c|c|c|c|c|c|c|c|c|}
\hline \multicolumn{4}{|c|}{ Langmuir parameters } & \multicolumn{3}{c|}{$\begin{array}{c}\text { Freundlich } \\
\text { parameters }\end{array}$} & \multicolumn{4}{c|}{ DKR parameters } & \multicolumn{3}{c|}{ Temkin parameters } \\
\hline $\boldsymbol{q}_{\boldsymbol{m}}$ & $\boldsymbol{b}$ & $\boldsymbol{R}^{2}$ & $\boldsymbol{K}$ & $\mathbf{1 / n}$ & $\boldsymbol{R}^{2}$ & $\boldsymbol{\beta}$ & $\boldsymbol{q}_{\boldsymbol{m}}$ & $\boldsymbol{E}$ & $\boldsymbol{R}^{2}$ & $\boldsymbol{A}_{\boldsymbol{T}}$ & $\boldsymbol{b}_{\boldsymbol{T}}$ & $\boldsymbol{R}^{2}$ \\
\hline 109.89 & 0.013 & 0.999 & 1.720 & 0.840 & 0.991 & $-1 \mathrm{E}-$ & 23.05 & 0.707 & 0.705 & 1.871 & 214.03 & 0.889 \\
0 & 5 & 7 & 2 & 3 & 9 & 06 & 7 & 1 & 5 & 2 & 0 & 3 \\
\hline
\end{tabular}


International Journal of Trend in Scientific Research and Development (IJTSRD) ISSN: 2456-6470

Table 2: Adsorption kinetic data for chromium (VI) biosorption by calcium alginate immobilized banana peels (Musa paradisiaca L.)

\begin{tabular}{|c|c|c|c|c|c|c|c|c|c|c|c|}
\hline \multicolumn{3}{|c|}{$\begin{array}{c}\text { Pseudo-first-order } \\
\text { model }\end{array}$} & \multicolumn{3}{|c|}{$\begin{array}{c}\text { Pseudo-second-order } \\
\text { model }\end{array}$} & \multicolumn{3}{|c|}{ Elovich model } & \multicolumn{3}{|c|}{$\begin{array}{c}\text { Intra-particle diffusion } \\
\text { model }\end{array}$} \\
\hline$q_{e}$ & $k_{1}$ & $R^{2}$ & $q_{e}$ & $k_{2}$ & $R^{2}$ & $\alpha$ & $\beta$ & $R^{2}$ & $\boldsymbol{K}_{i}$ & $C$ & $R^{2}$ \\
\hline $\begin{array}{c}1.098 \\
6\end{array}$ & $\begin{array}{c}0.007 \\
6\end{array}$ & $\begin{array}{c}0.941 \\
8\end{array}$ & $\begin{array}{c}2.002 \\
0\end{array}$ & $\begin{array}{c}0.012 \\
9\end{array}$ & 0.9606 & $\begin{array}{c}0.173 \\
6\end{array}$ & $\begin{array}{c}2.777 \\
0\end{array}$ & $\begin{array}{c}0.912 \\
0\end{array}$ & 0.0922 & $\begin{array}{c}0.395 \\
2\end{array}$ & 0.9587 \\
\hline
\end{tabular}

Table 3: Thermodynamic parameters of chromium (VI) biosorption by calcium alginate immobilized banana peels (Musa paradisiaca $\mathrm{L}$.)

\begin{tabular}{|c|c|c|c|c|c|c|}
\hline $\begin{array}{l}\text { Sr. } \\
\text { No. }\end{array}$ & $\begin{array}{c}\text { Temperature } \\
\left({ }^{0} \mathrm{C}\right)\end{array}$ & $\begin{array}{c}\text { Temperature } \\
\text { (K) }\end{array}$ & $K c$ & $\begin{array}{c}-\Delta G^{0} \\
(\mathrm{KJ} / \mathrm{mol})\end{array}$ & $\begin{array}{c}\Delta H^{0} \\
(\mathrm{KJ} / \mathrm{mol})\end{array}$ & $\begin{array}{c}\Delta S^{0} \\
(\mathbf{J} / \mathbf{m o l})\end{array}$ \\
\hline 1 & $20^{\circ} \mathrm{C}$ & 293 & 3.5516 & 0.5015 & \multirow{4}{*}{29.9885} & \multirow{4}{*}{113.07} \\
\hline 2 & $25^{0} \mathrm{C}$ & 298 & 4.2714 & 0.5321 & & \\
\hline 3 & $30^{\circ} \mathrm{C}$ & 303 & 6.9872 & 0.5461 & & \\
\hline 4 & & 313 & 7.0645 & 0.5956 & & \\
\hline
\end{tabular}

